\title{
Erwartungshaltung vs. Entwicklungsdauer: Impfstoffe bei internationalen Notlagen
}

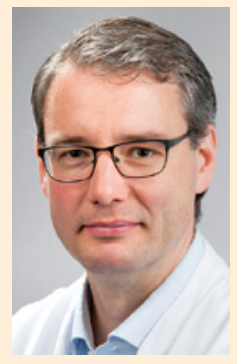

Sehr geehrte Kolleginnen und Kollegen,

Impfungen schützen vor Infektionskrankheiten. Sinnvoll und konsequent eingesetzt, können Impfstoffe neben einer Individualprotektion (z. B. bei Reisenden) auch Auswirkungen auf die Epidemiologie von Infektionskrankheiten und somit auf die Krankheitslast in der Bevölkerung insgesamt haben. Zunehmende Aktivitäten und verbesserte Methoden / Technologien sowohl aufseiten der epidemiologischen Surveillance als auch in der Impfstoffentwicklung scheinen in den letzten Jahren zu einer gesteigerten Dynamik beizutragen. Surveillance ist dabei insbesondere auch nach Einführung von Impfstoffen wichtig, um den Erfolg von Impfstoffen jenseits der Individualprotektion angesichts knapper Mittel in den Gesundheitswesen kontinuierlich zu überprüfen. Andererseits spielt die öffentliche (und damit politische) Aufmerksamkeit eine erhebliche Rolle darin, ob/wann/ welche Impfstoffkandidaten tatsächlich in Richtung einer Marktzulassung gebracht werden. Zu nennen ist dabei nicht nur die Zulassung eines ersten Dengueimpfstoffs in einigen endemischen Ländern Ende des vergangenen Jahres. Bemerkenswert ist in diesem Zusammenhang auch, dass ein Ebolaausbruch erst das Ausmaß einer „Public Health Emergency of International Concern (PHEIC)“ - so nennt die WHO etwas umständlich eine international bedeutende gesundheitliche Notlage - erreichen musste, um bereits seit langer Zeit existierende Impfstoffkandidaten aus der präklinischen Forschung in die klinische Entwicklung überführen zu können. Ein erneuter PHEIC wurde nun am 1. Februar in Bezug auf das Zika-Virus ausgerufen - und auch hier ist der Ruf nach Impfstoffen gegenwärtig sehr laut. Es bleibt zu berücksichtigen, dass die öffentliche/politische Debatte um die Notwendigkeit von Impfstoffen wieder einmal deutlich kürzer sein wird als die klinische Entwicklung bis zur Marktzulassung. Eine sich auf Seiten der Öffentlichkeit möglicherweise ändernde Erwartungshaltung in Bezug auf die rasche Bereitstellung von Interventionen zu neuen Infektionsgefahren wie zum Beispiel die Entwicklung neuer Impfstoffe muss jedoch auch auf Seiten der Regulierer neue Möglichkeiten für die beschleunigte klinische Prüfung und Zulassung zum Beispiel im Rahmen von Ausbruchsgeschehen eröffnen. Dass langfristige und im Rahmen funktionierender internationaler Kooperationen umgesetzte Strategien zum Einsatz von Impfstoffen tatsächlich Infektionskrankheiten komplett auslöschen können, wird sich nach der Pockeneradikation 1980 hoffentlich in den kommenden Jahren auch für die Kinderlähmung bewahrheiten. Dabei steht in diesem Monat April ein bedeutender Schritt an: In einer konzertierten Aktion wollen 155 Länder und Territorien die Verwendung des trivalenten Impfstoffs ein- und auf bivalenten Impfstoff umstellen, sodass es fortan keine Infektionen durch Poliovirus Typ 2 mehr geben sollte (auch hier war die entsprechende PHEIC-Warnung vielleicht hilfreich).

Auch in der aktuellen Ausgabe dieser Zeitschrift findet sich das Thema Impfen in mehreren Beiträgen. So widmen sich die Kollegen Schmolz, Ley-Köllstadt, Hülße in ihrem Artikel der Meningitisimpfung, die ja gleichfalls in der jüngeren Vergangenheit durch die Entwicklung konjugierter tetravalenter Impfstoffe gegen die Serogruppen A, C, $\mathrm{W}$ und $\mathrm{Y}$ sowie in Bezug auf die Impfung gegen die Serogruppe B erhebliche Fortschritte erzielen konnte - und insbesondere der Einsatz des monovalenten konjugierten Serogruppe-A-Impfstoffs in afrikanischen Ländern dürfte unsere gewohnten epidemiologischen Karten („Meningitisgürtel“) verändern. Reisen - insbesondere zum Zwecke des Besuches (oder Teilnahme) an sportlichen Großereignissen wie der Olympischen Spiele in Rio in diesem Sommer - geht nicht nur mit Infektionsgefahren einher, auch wenn der aktuelle Zikaausbruch in Lateinamerika diesen Eindruck möglicherweise verstärkt. Einem anderen Thema widmet sich hingegen Kollege Pippig. In seinem Beitrag zu fachorthopädischen Anforderungen an militärische Luftfahrzeugführer wird auch dem nicht Eingeweihten deutlich, welchen Belastungen Piloten in diesem Bereich ausgesetzt sind.

Hoffentlich haben Sie beim Lesen dieser Ausgabe viel Freude.

Mit freundlichen Grüßen aus Hamburg/Zürich

Ihr PD Dr. Jakob Cramer 